\title{
Mucosal immune defence mechanisms in enterocolitis complicating Hirschsprung's disease
}

\author{
A Imamura, P Puri, D S O'Briain, D J Reen
}

\begin{abstract}
Enterocolitis remains an important cause of morbidity and mortality in Hirschsprung's disease. The aetiology of enterocolitis is uncertain - ischaemic and bacterial causes and recently, rotavirus infections, have been suggested. Bowel tissue from 12 patients with Hirschsprung's disease who underwent Swenson's operation (five of whom had clinical evidence of enterocolitis) and colon from six controls subjects were examined to investigate possible immunopathological mechanisms associated with the disease. IgA, IgM, and J chain (but not IgG) containing plasma cells were significantly increased in the lamina propria along the entire length of resected bowel in enterocolitis patients, compared with non-enterocolitis patients and controls $(\mathbf{p}<\mathbf{0 . 0 1})$. Luminal secretory component staining of the anganglionic segment of colon from enterocolitis patients was considerably reduced. Lamina propria CD68 positive monocyte/macrophages and CD45RO positive leukocytes were increased in enterocolitis patients compared with non-enterocolitis patients $(\mathrm{p}<0.01)$. CD57 positive natural killer (NK) cells showed a unique distribution pattern compared with other cell types. Patients with enterocolitis showed a significant increase in CD57 positive NK cells in the lamina propria of ganglionic bowel only $(p<0.05)$. NK cell values in ganglionic bowel of non-enterocolitis patients and in aganglionic bowel in all patients were similar to controls. The diversity of altered local immune response seen in this study may reflect a multifactorial microbial aetiology in enterocolitis associated with Hirschsprung's disease.
\end{abstract}

Enterocolitis continues to be the major cause of morbidity and mortality in patients with Hirschsprung's disease, with an incidence ranging from 20 to $58 \% .^{1-3}$ Relapses of enterocolitis can occur despite a defunctioning colostomy and after a definitive pull-through operation. ${ }^{3+}$ It has been reported that patients with enterocolitis complicating Hirschsprung's disease have persistent inflammatory changes in the excluded large bowel after diversion of the faecal stream by colostomy. ${ }^{35}$ The pathogenesis of the enterocolitis remains poorly understood, but many theories have been advanced to explain its occurrence. These include: mechanical dilatation and faecal stasis, ' alteration in mucin components, ${ }^{36}$ increased prostaglandin $E_{1}$ activity, ${ }^{7}$ Clostridium difficile infection, ${ }^{8}$ and more recently rotavirus infection. ${ }^{9}$ To pursue further a possible infectious aetiology in relation to enterocolitis in Hirschsprung's disease, we have investigated immunological changes in the colon in two groups of patients with this disorder, one with persistent enterocolitis and the other no evidence of this

\section{Methods}

PATIENTS

The entire resected specimen of colon was obtained from 12 patients with Hirschsprung's disease after Swenson's operation (age range, six to 24 months; mean, 10.5 months). Five patients had symptomatic enterocolitis before defunctioning colostomy or ileostomy was performed. Colonic tissues from six patients, taken during closure of colostomy for imperforate anus, acted as controls. The entire resected specimen of colon was cut at $0.5 \mathrm{~cm}$ intervals and examined serially by routine haematoxylin and eosin ( $\mathrm{H}$ and $\mathrm{E}$ ) and by immunoperoxidase staining.

\section{IMMUNOCYTOCHEMISTRY}

Sections $(4 \mu)$ from ganglionic and aganglionic colon were deparaffinised. For selected antibodies, trypsinisation was performed in $0.1 \%$ trypsin (Sigma Ltd.) and $0 \cdot 1 \%$ calcium chloride for 30 minutes at $37^{\circ} \mathrm{C}$. Endogenous peroxidase activity was inactivated by methanol and hydrogen peroxide. ${ }^{10}$ Sections were then flooded with $10 \%$ species specific normal serum to minimise non-specific antibody binding. Sections were incubated with primary antisera in a moist chamber at $4^{\circ} \mathrm{C}$ for 2 to 16 hours. After washing in PBS, antibodies to plasma cell isotypes, lymphocytes, natural killer (NK) cells, macrophages, J chain, and secretory component were demonstrated by either direct immunoperoxidase staining or by the streptavidin-biotin complex method." Staining was visualised using $0.025 \%$ diaminobenzidine (DAB) solution in a $50 \mathrm{mmol} / \mathrm{l}$ Tris-HCI buffer $(\mathrm{pH} \mathrm{7.6})$ containing $10 \mathrm{mmol} / \mathrm{l}$ hydrogen peroxide. Counterstaining was performed with $1 \%$ methyl green solution (pH 4.0). The specificity of immunohistochemical staining was confirmed by the use of an appropriate concentration of non-immune serum. Positively stained immunocytes were counted in 10 visual fields from two sections each from aganglionic and ganglionic specimens of bowel, using a $40 \mathrm{X}$ objective. The results were expressed as the number of cells per $\mathrm{mm}^{2}$ of tissue, using a calibrated eyepiece square graticule.

ANTISERA

Primary antisera used were as follows: 
horseradish peroxidase (HRP) labelled antihuman IgG, IgA, IgM (Tago, Inc.); HRP labelled anti-human secretory component (Dakopatts); rabbit anti-human $\mathrm{J}$ chain (Nordic); antiUCHL-1 (CD45RO, Dakopatts), anti-KP-1 (CD68, Dakopatts), anti-Leu-7 (CD57, BectonDickinson), anti-Chromogranin A (Dakopatts). The second layer antibodies used were: biotinylated $\mathrm{F}(\mathrm{ab})_{2}$ fragment rabbit anti-mouse IgG and biotinylated $F(a b)_{2}$ fragment swine antirabbit IgG (Dakopatts). The streptavadin-biotin complex HRP detection system was obtained from Dakopatts.

\section{STATISTICS}

Tests for significant differences between the patient populations were performed using the Student's $t$ test.

\section{Results}

H AND E STAINING

The five patients who had clinical evidence of enterocolitis before defunctioning colostomy also showed histological evidence of enterocolitis in the resected specimen of bowel. $\mathrm{H}$ and $\mathrm{E}$ staining showed crypt abscesses, increased lymphoid infiltration of the lamina propria, and hyperplastic lymphoid follicles with enlarged germinal centres throughout the entire excluded bowel.

\section{IMMUNOCYTOCHEMISTRY}

\section{Plasma cell isotypes}

IgA, IgM, and IgG containing plasma cells were seen throughout the lamina propria in patients and controls (Fig 1). IgA containing plasma cells were significantly increased along the entire length of resected bowel in enterocolitis patients compared with non-enterocolitis and control tissues $(p<0 \cdot 01)$. Four of the five enterocolitis cases had minimal luminal IgA staining in aganglionic bowel (Fig 2). The numbers of IgM and IgG containing plasma cells in the lamina propria in all groups were much less than the number of IgA containing plasma cells. While IgG containing plasma cells showed no significant difference between groups, IgM containing plasma cells were increased in enterocolitis compared with non-enterocolitis $(\mathrm{p}<0.02)$ and control $(\mathrm{p}<0.01)$ tissues (Fig 1$)$.

\section{J chain and secretory component}

$\mathrm{J}$ chain immunoreactivity was seen in columnar cells of the epithelium and in plasma cells in the lamina propria in patients and controls. J chain containing plasma cells in the lamina propria were significantly increased in patients with enterocolitis compared with non-enterocolitis $(\mathrm{p}<0.02)$ and control $(\mathrm{p}<0.01)$ subjects (Fig 3). Secretory component staining of the aganglionic segment of colon in patients with enterocolitis showed an intensely granular pattern in the supranuclear space and a faint homogenous cytoplasmic staining pattern in columnar cells
(Fig 4A). However, all these patients had considerably reduced secretory component immunostaining on the luminal surface of epithelial cells in the aganglionic segment. Colonic tissue from non-enterocolitis and control subjects showed a different staining pattern from colitis patients; there was secretory component staining in the basolateral plasma membrane, in the cytoplasm, and in the absorptive surfaces of columnar cells (Fig 4B).

\section{CD45RO positive leukocytes and CD68 positive macrophages}

Memory $\mathrm{T}$ cells as well as monocytes and granuloctyes recognised by the $\mathrm{CD} 45 \mathrm{RO}$ antigen were significantly increased in enterocolitis cases $(\mathrm{p}<0.01)$ (Fig 5).

The numbers of CD68 positive macrophages in the lamina propria of enterocolitis patients were significantly increased compared with those of normal colon and non-enterocolitis cases $(\mathrm{p}<0.01)($ Fig 5).

\section{NK cells}

CD57 positive NK cells were distributed in both
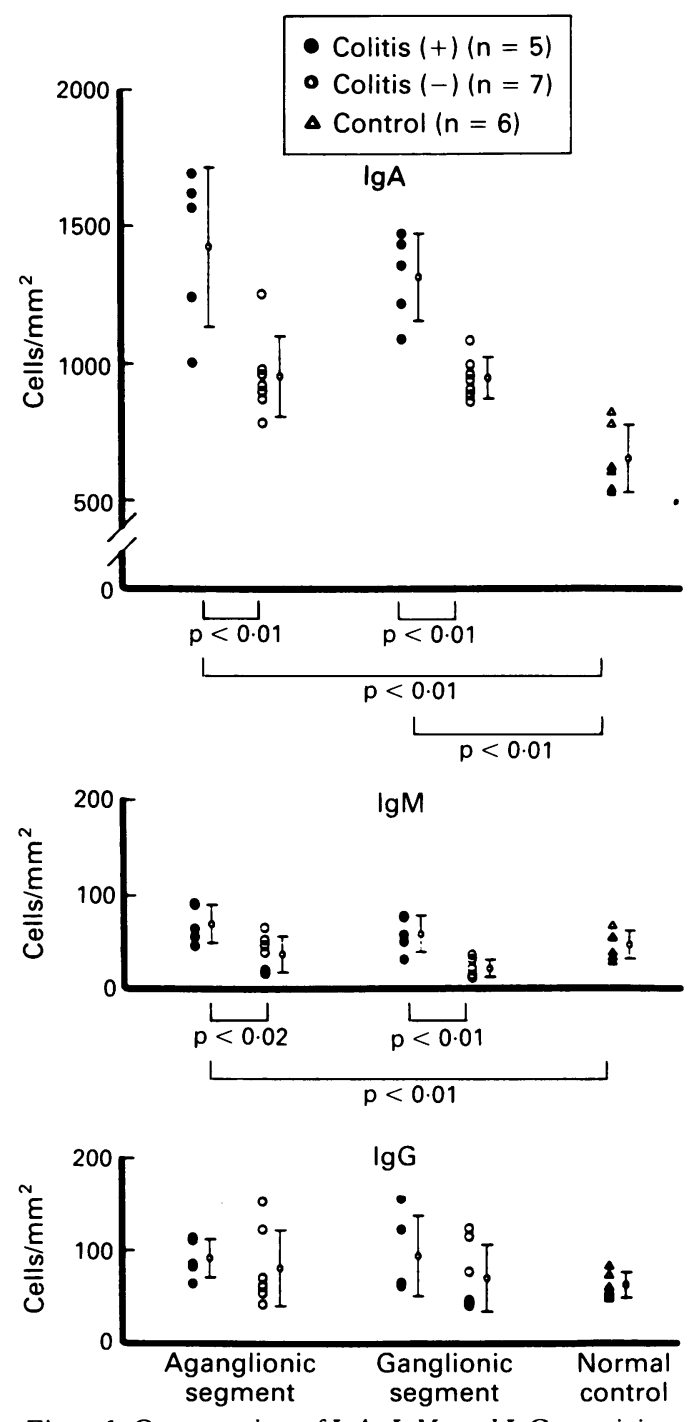

Figure 1: Concentrations of IgA, IgM, and IgG containing plasma cells in the lamina propria of enterocolitis, nonenterocolitis, and control subjects. 
lymphoid follicles and in the lamina propria of patients and controls (Fig 6). NK cells in the lamina propria were significantly increased in the ganglionic segment of colon from patients with enterocolitis compared with nonenterocolitis and control subjects $(\mathrm{p}<0.05)$ (Fig 7). By contrast, no difference in NK cell distribution in the lamina propria or germinal centres of the aganglionic portion of bowel were seen in different patient groups and controls. There was, in addition, some positive staining of cells in the epithelium (Fig 6B). These cells showed the typical flask like appearance of endocrine cells. As CD57 is known to stain both NK cells and endocrine cells, ${ }^{12}{ }^{13}$ the endocrine nature of these epithelial cells was confirmed, using a double staining technique ${ }^{14}$ with antiChromogranin A and anti-CD57 antibodies. Colonic epithelium from enterocolitis patients expressed a much greater number of these cells in the distal aganglionic region than that from non-enterocolitis cases.

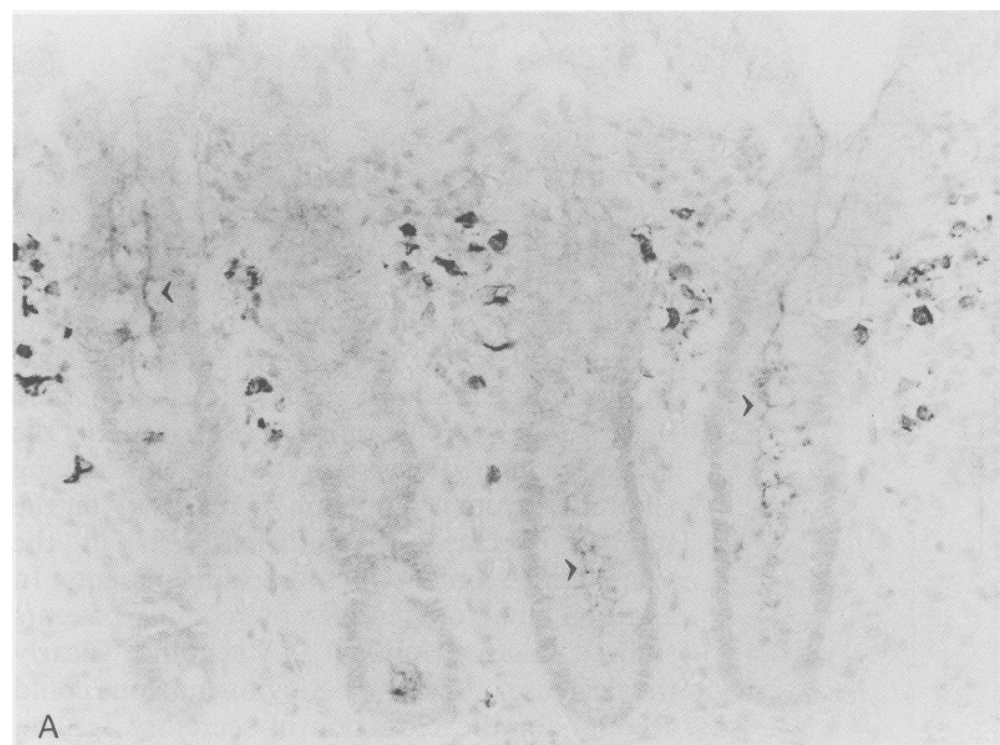

Figure 2: IgA staining in the lamina propria and epithelial cells. (A) Aganglionic segment from non-enterocolitis patient: normal levels of IgA containing plasma cells and surface epithelial cell staining (arrow head) are seen (original magnification $\times 320$ ). (B) Aganglionic segment from enterocolitis patient; considerably increased IgA containing plasma cells are seen in the lamina propria. Only minimal surface IgA staining is seen in the epithelium (original magnification propria.
$\times 320$.

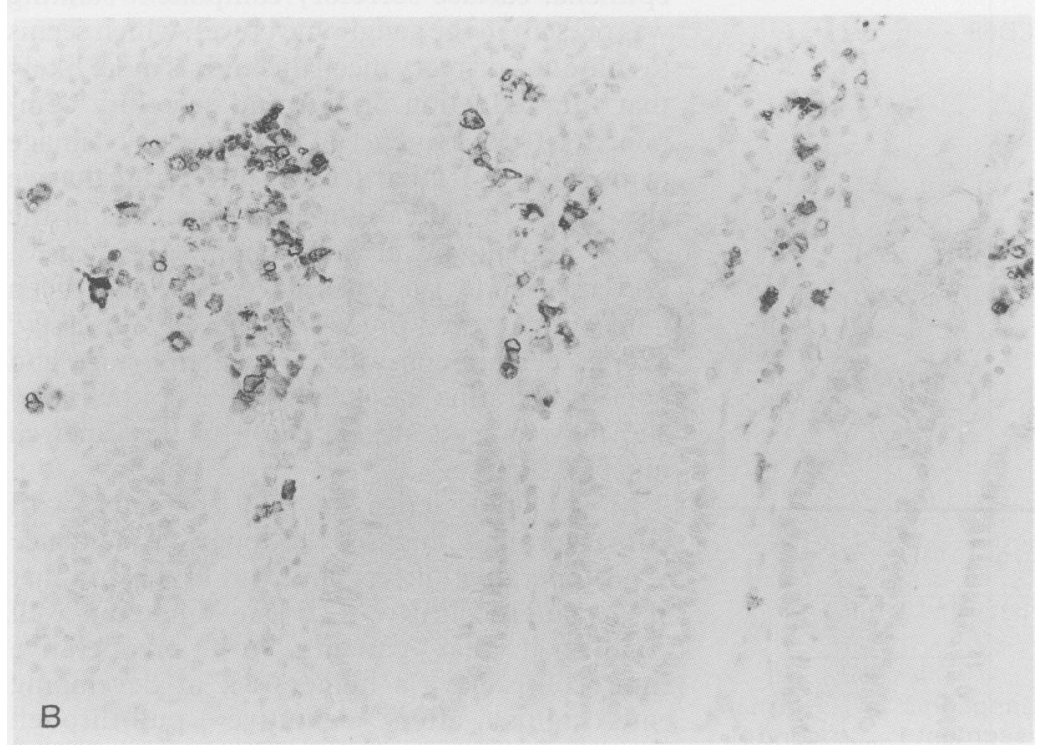

\section{Discussion}

This study confirms our previously reported findings that Hirschsprung's disease patients who present clinically with enterocolitis show histological evidence of enterocolitis both in the ganglionic and aganglionic bowel several months after diversion of the faecal stream by colostomy. The results also show significant changes in the mucosal immune response throughout the resected colon in patients with persistent enterocolitis. While there was a general increase in all inflammatory cell types investigated, there was a disproportionate increase in NK cells infiltrating the ganglionic segment of bowel in enterocolitis compared with non-enterocolitis patients. NK cell levels in aganglionic segment of colon in both enterocolitis and non-enterocolitis patients were similar to those in controls. Previous studies have suggested that enterocolitis occurs only in the dilated ganglionic bowel of patients with Hirschsprung's disease. ${ }^{15-17}$ While this study demonstrates inflammatory changes throughout the resected segment in enterocolitis patients, increased NK cell infiltration was confined to the ganglionic segment of bowel in these patients.

The major biological functions of NK cells are those of antitumour and antiviral responses, as well as their more recently described function as potential regulators of antibody production. ${ }^{18-20}$ If we are to attach particular significance to the differential pattern of NK cell infiltration in enterocolitis cases, then their function as effector cells of antiviral immunity is their most likely role in this condition. Recently, several peptides described as neurotransmitters have been shown to modulate the immune response in the gastrointestinal tract. ${ }^{21}$ Because of the known abnormalities in peptidergic nerves in Hirschsprung's disease, it is possible that the regional abnormality of NK cell infiltration may be related to regional abnormalities in neuropeptides.

Secretory $\operatorname{IgA}$ is the major immunoglobulin isotype providing immunoprotection in the

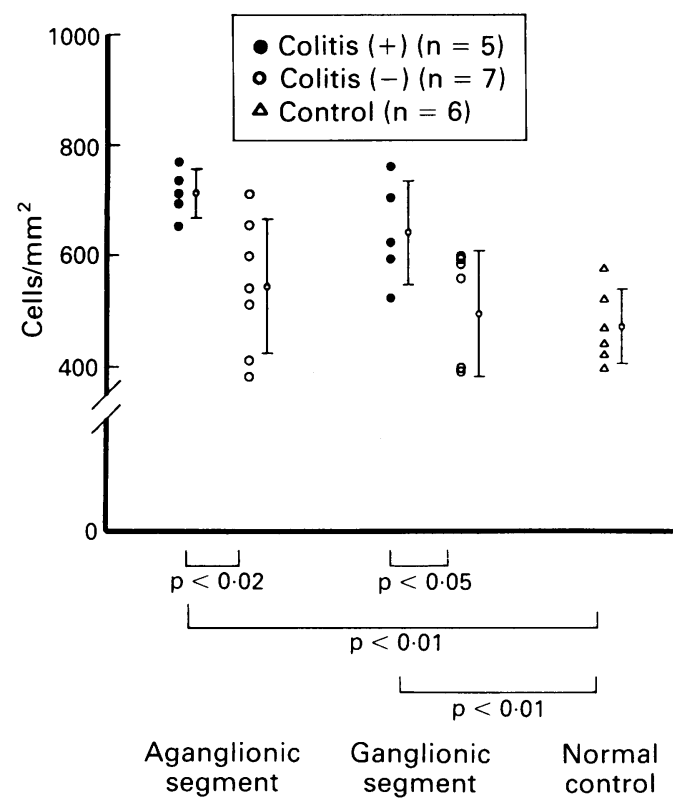

Figure 3: Levels of $\mathcal{F}$ chain containing plasma cells in the lamina propria of enterocolitis, non-enterocolitis, and control subjects. 
Figure 4: Secretory component staining in epithelial cells. (A)

Aganglionic segment from enterocolitis patient: supranuclear granular and faint homogenous cytoplasmic staining, but only minimal surface staining is seen in columnar cells (original magnification $\times 400)$. (B) Aganglionic segment from nonenterocolitis patient: secretory component staining is seen in the basolateral plasma membrane, in the cytoplasm, and in the absorptive surfaces (arrow head) of columnar cells (original magnification $\times 400$ ).
Figure 5: Levels of $C D 45 R O$ and $C D 68$ positive leukocytes and macrophages in the lamina propria of enterocolitis, nonenterocolitis and control subjects.
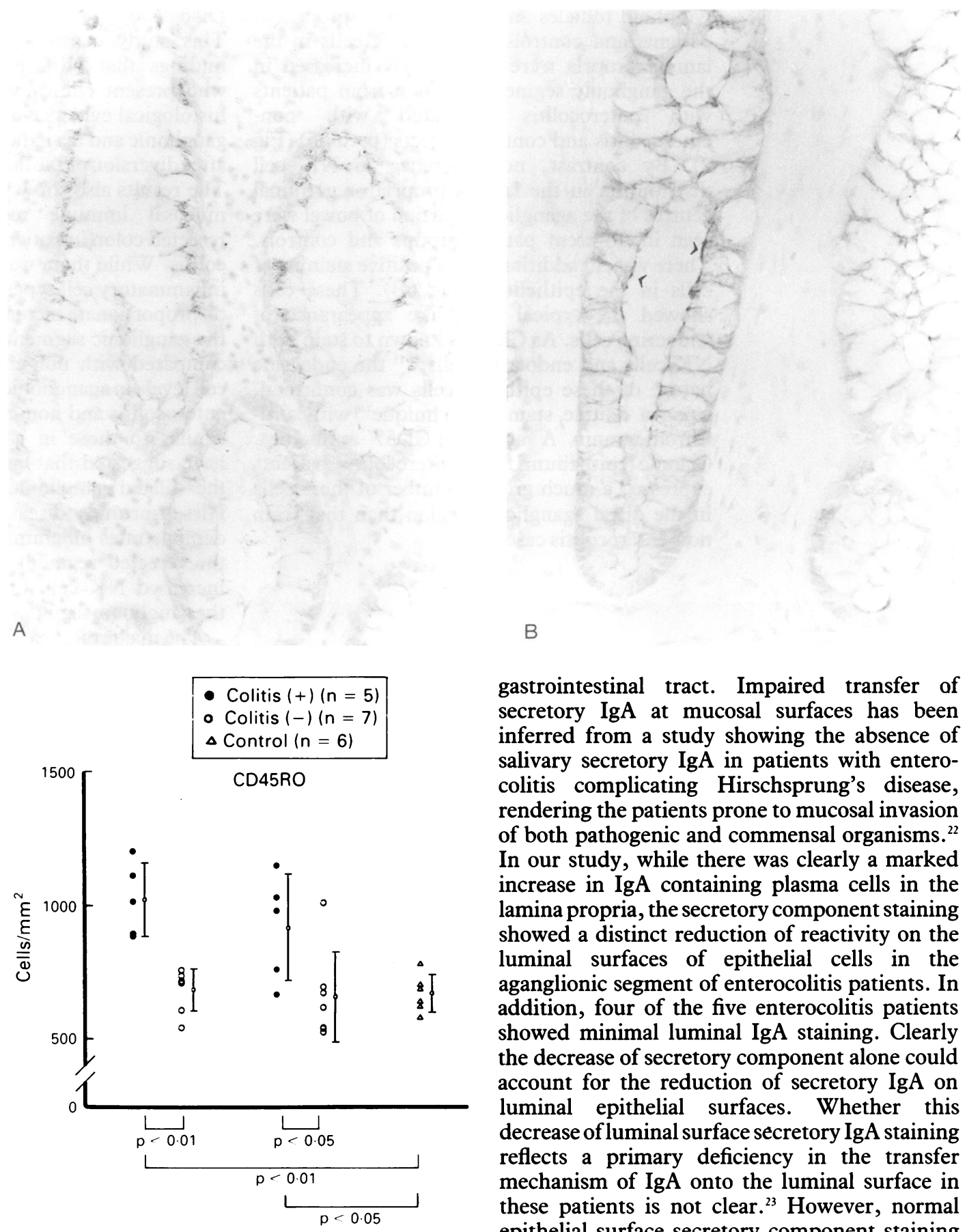

gastrointestinal tract. Impaired transfer of secretory IgA at mucosal surfaces has been inferred from a study showing the absence of salivary secretory $\operatorname{IgA}$ in patients with enterocolitis complicating Hirschsprung's disease, rendering the patients prone to mucosal invasion of both pathogenic and commensal organisms. ${ }^{22}$ In our study, while there was clearly a marked increase in IgA containing plasma cells in the lamina propria, the secretory component staining showed a distinct reduction of reactivity on the luminal surfaces of epithelial cells in the aganglionic segment of enterocolitis patients. In addition, four of the five enterocolitis patients showed minimal luminal IgA staining. Clearly the decrease of secretory component alone could account for the reduction of secretory IgA on luminal epithelial surfaces. Whether this decrease of luminal surface secretory IgA staining reflects a primary deficiency in the transfer mechanism of IgA onto the luminal surface in these patients is not clear. ${ }^{23}$ However, normal epithelial surface secretory component staining was present in the ganglionic bowel, which seems to rule out a primary mechanism. It is more likely that this reduction of $\operatorname{IgA}$ and secretory component is a consequence of inflammatory damage to the mucosa. It is particularly interesting that we also noted an increase in endocrine cells in the distal aganglionic area of enterocolitis cases. Increased endocrine cells have previously been noted in damaged mucosa of Crohn's disease..$^{2+}$ These cells are considered to be end stage and non-proliferating basal cells in the epithelium, ${ }^{25}$ and may indicate degeneration of the renewed mucosal surface.

In a large series of 880 patients with Hirschsprung's disease, the reported incidence of postoperative enterocolitis was $11.5 \%$ and that of late enterocolitis was $22.5 \%{ }^{+}$While it is well established that patients with preoperative enterocolitis have a higher risk of developing enterocolitis after definitive pull-through 

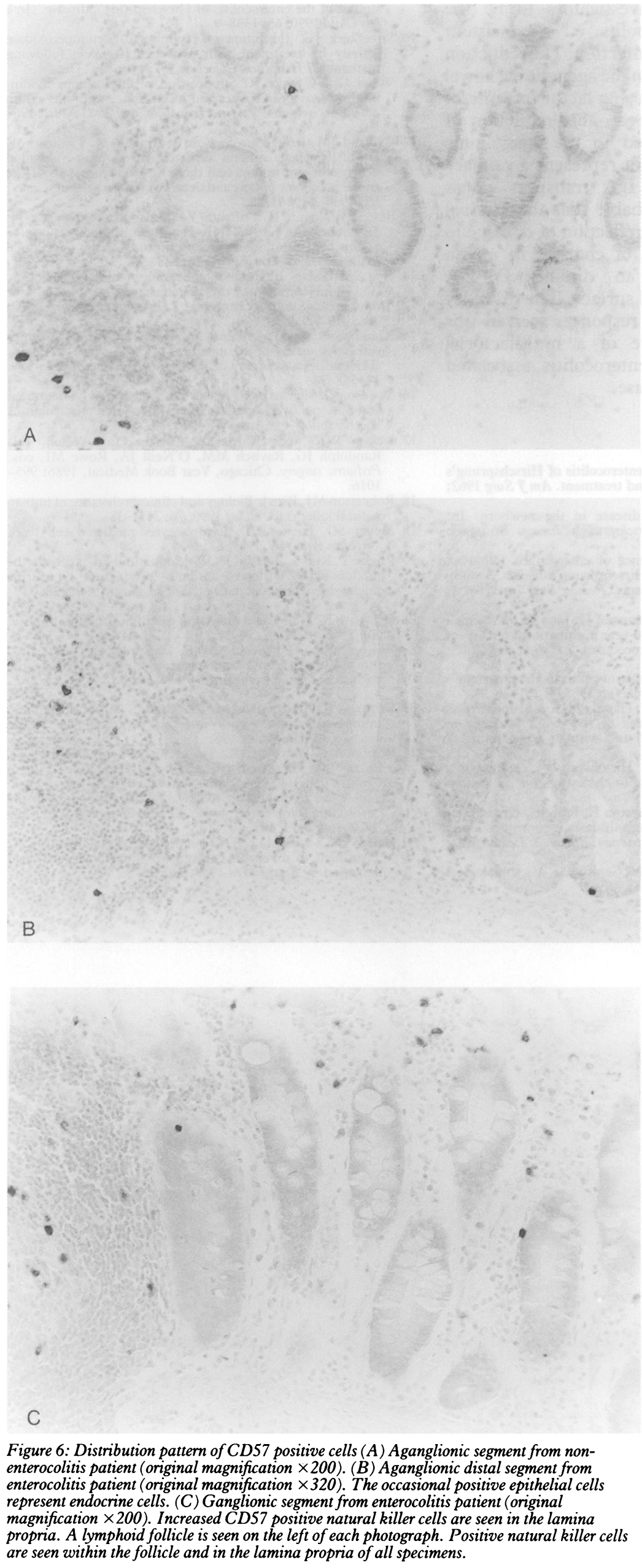

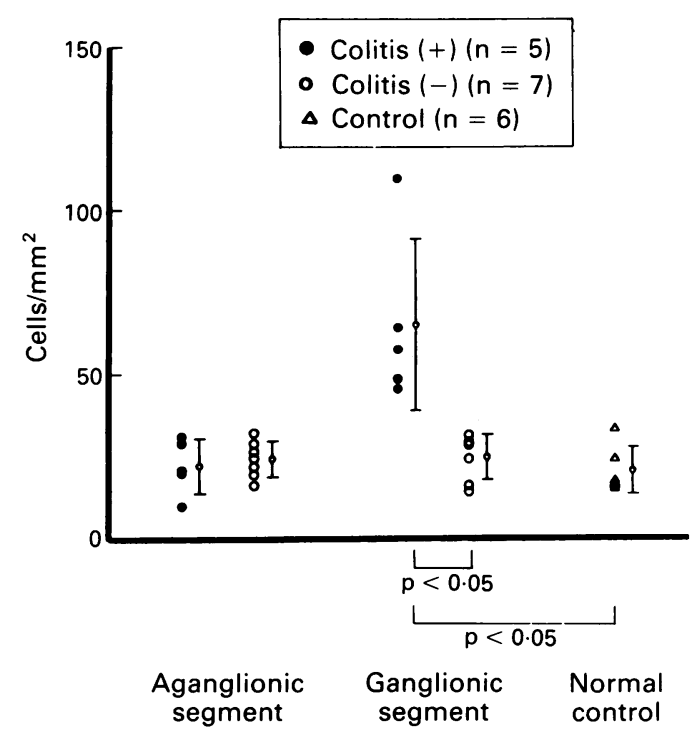

Figure 7: Levels of CD57 positive natural killer cells in the lamina propria of enterocolitis, non-enterocolitis and control subjects.

operation, it is also clear that in many patients, enterocolitis only appears postoperatively or as a late complication. Our study suggests that the pulled-through bowel of patients with enterocolitis complicating Hirschsprung's disease may have significant persistent inflammatory changes, given our observation of histological and immunological evidence of inflammation along the entire resected segment of bowel. While the presence of inflammatory changes in the pulled-through bowel could be a predisposing factor in the development of enterocolitis after definitive surgery in some cases, it does not, however, explain the occurrence of enterocolitis in patients in whom enterocolitis did not exist preoperatively.

Colitis occurring in segments of colon excluded from the faecal stream has been defined as a specific condition termed diversion colitis. Recently, it has been suggested that in adults, the disorder is caused by a deficiency of short chain fatty acids (SCFA) and may be corrected by local SCFA supplementation. ${ }^{26}$ Many of the features of persistent enterocolitis resemble those described in diversion colitis. Diversion colitis manifests several months after diversion, there is a similar histology, and the colon reverts to normal after reanastomosis. However, the finding that the patients with histological evidence of enterocolitis at the time of definitive surgery had clinical enterocolitis before defunctioning colostomy, suggests that while diversion colitis may be a contributing factor, the enterocolitis of Hirschsprung's disease is more complex. Until more is known about the immunological abnormalities of diversion colitis and the role of SCFA in the nutrition of the infant colon, the relationship between the enterocolitis of Hirschsprung's disease and diversion colitis will remain undefined.

The aetiology of Hirschsprung's disease associated enterocolitis remains a complex issue but this study has provided further support for a possible infectious aetiology of the enterocolitis. Increased NK cell responses confined to the ganglionic bowel, the site which has been 
considered by many investigators to be the primary focus of enterocolits, ${ }^{16-18}$ is consistent with a possible local viral infection. The reduction of luminal secretory IgA in the aganglionic bowel may be a further predisposing factor to a microbial pathogenesis. However, this reduction of secretory $\operatorname{IgA}$ is confined to the aganglionic portion only, and does not represent a primary deficiency in secretory $\operatorname{IgA}$ transport across epithelial cells. It is probable that the luminal IgA deficiency is more a reflection of damage to the mucsoal surfaces or of changes in mucin composition, ${ }^{36}$ leading to diminished $\operatorname{IgA}$ adherence to the mucosal surface. The diversity of altered local immune responses seen in this study may be reflective of a multifactorial microbial aetiology in enterocolitis associated with Hirschsprung's disease.

1 Bill AH, Chapman ND. The enterocolitis of Hirschsprung's disease. Its natural history and treatment. Am $\mathcal{F}$ Surg 1962; disease. It $70-4$

2 Nixon HH. Hirschsprung's disease in the newborn. In: Holschneider AM, ed. Hirschsprung's disease. Stuttgart: Hippokrates, 1982: 103-13.

3 Fujimoto T, Puri P. Persistence of enterocolitis following diversion of faecal stream in Hirschsprung's disease. A study of mucosal defence mechanisms. Pediatr Surg Int 1988; 3 : $141-6$.

4 Sherman JO, Snyder ME, Weitzmann JJ, Jona JZ, O'Donnell B, Carcassonne M, et al. A 40-year multinational retrospecB, Carcassonne $M$, et al. A 40-year multinational retrospec-
tive study of 880 Swenson procedures. F Pediatr Surg 1989 ; tive study $833-8$

5 Lifschitz CH, Bloss R. Persistence of colitis in Hirschsprung's disease. F Pediatr Gastroenterol Nutr 1985; 4: 291-3.

6 Akkary S, Sahwy E, Kandil W, Hamdy MH. A histochemical study of the mucosubstances of the colon in cases of Hirschsprung's disease with and without enterocolitis. $\mathcal{F}$ Pediatr Surg 1981; 16: 664-8.

7 Lloyd-Still JD, Demers LM. Hirschsprung's enterocolitis, Prostaglandins, and response to cholestyramine. $\mathcal{F}$ Pediat Surg 1978; 13: 417-8.

8 Thomas DFM, Fernie DS, Bayston R, Spitz L, Nixon HH Enterocolitis in Hirschsprung's disease: A controlled study of the etiologic role of Clostridium difficle. $\mathcal{F}$ Pediatr Surg 1986; 21: 22-5.

9 Wilson-Storey D, Scobie WG, McGenity KG. Microbiological studies of the enterocolitis of Hirschsprung's disease. Arch Dis Child 1990; 65: 1338-9.

10 Streefkerk JG. Inhibition of erythrocyte pseudoperoxidase activity by treatment with hydrogen peroxide following methanol. F Histochem Cytochem 1972; 20: 829-31.

11 Wood GS, Warnke R. Suppression of endogenous avidinbinding activity in tissues and its relevance to biotin-avidin binding activity in tissues and its relevance to biotin-avidin 204.

12 Caillaud JM, Benjelloun S, Bosq J, Braham K, Lipinski M HNK-1-defined antigen detected in paraffin-embedded neuroectoderm tumors and those derived from cells of the amine precursor uptake and decarboxylation system. Cancer Res 1984; 44: 4432-5.

13 Shioda Y, Nagura H, Tsutsumi Y, Shimamura K, Tamaoki N. Distribution of Leu7 (HNK-1) antigen in human digestive organs: an immunohistochemical study with monoclonal antibody. Histochem $\mathcal{F}$ 1984; 16: 843-54.

14 Hsu SM, Soban E Color modification of diaminobenzidine (DAB) precipitation by metallic ions and its application for double immunohistochemistry. F Histochem Cytochem 1982; double immun $1079-82$.

15 Kleinhaus S, Boley SJ, Sheran M, Sieber WK. Hirschsprung's disease-A survey of the members of the surgical section of the American Academy of Pediatrics. 7 Pediatr Surg 1979 14: 588-97.

16 Swenson O, Sherman JO, Fisher JH, Cohen E. The treatmen and postoperative complications of congenital megacolon. A 25 year follow-up. Ann Surg 1975; 182: 266-73.

17 Sieber WK. Hirschsprung's disease. In: Welch KJ Randolph JG, Ravitch MM, O'Neill JA, Rowe MI, eds. Pediatric surgery. Chicago, Year Book Medical, 1986: 9951016.

18 Robertson MJ, Ritz J. Biology and clinical relevance of human natural killer cells. Blood 1990; 76: 2421-38.

19 Meuer SC, Dienes HP. Lymphocytes mediated cell lysis. Virchows Arch [B]. 1989; 57: 1-9.

20 Priebe T, Ruiz L, Nelson JA. Role of natural killer cells in the modulation of primary antibody production by purine nucleosides and their analogs. Cell Immunol 1990; 130: 513 9

21 O'Doriso MS. Neuropeptides and gastrointestinal immunity. Am ₹ Med 1986; 81: 74-82.

22 Wilson-Storey D, Scobie WG. Impaired gastrointestinal mucosal defense in Hirschsprung's disease: A clue to the mucosal defense in Hirschsprung's disease: A clue to the
pathogenesis of enterocolitis? F Pediatr Surg 1989; 24: 4624.

23 Brown WR, Isobe Y, Nakane PK. Studies on translocation of immunoglobulins across intestinal epithelium. Gastroenterology 1976; 71. 985-95.

24 Bishop AE, Pietroletti R, Taat CW, Brummelkamp WH, Polak JM. Increased populations of endocrine cells in Crohn's ileitis. Virchows Arch [A] 1987; 410: 391-6.

25 Chang WW. Leblond CP. Renewal of the epithelium in the descending colon of the mouse. Renewal of argentafin cells Am F Anat 1971; 131: 101-10.

26 Harig JM, Soergel KH, Komorowski RA, Wood CM. Treatment of diversion colitis with short-chain-fatty acid irrigation. N Engl f Med 1989; 320: 23-8. 